\title{
FORMULATION AND EVALUATION OF TRANSDERMAL PATCHES OF METOPROLOL TARTRATE USING PERMEATION ENHANCERS OF NATURAL AND SYNTHETIC ORIGIN
}

\author{
SHIKHA BAGHEL CHAUHAN ${ }^{*}$, SUSHILA SAINI ${ }^{2}$
}

${ }^{* 1}$ Department of Pharmaceutics, Amity Institute of Pharmacy, Amity University, Noida, Uttar Pradesh, India, ${ }^{2}$ Research Scholar, Department of Pharmaceutics, Amity Institute of Pharmacy, Amity University, Noida, Uttar Pradesh, India

Email: shikha.pharma@gmail.com

Received: 23 Feb 2019, Revised and Accepted: 06 Aug 2019

\section{ABSTRACT}

Objective: Oral metoprolol tartrate has a short elimination half-life (2-3h) and low bioavailability undergoes extensive first-pass metabolism and frequent dosing. The aim of the present investigation was to formulate, develop and evaluate metoprolol tartrate transdermal patches using various synthetic and natural penetration enhancers.

Methods: Enhancers used were eugenol, limonene, basil oil, urea and SLS (sodium lauryl sulphate). Polymer used was chitosan and PEG 400 used as a plasticizer. Transdermal Films were prepared by using solvent casting method. FTIR and DSC were studied to assess any interaction between the drug and polymers. Films were evaluated for Physico-chemical Characteristics like thickness, weight variation, folding endurance, moisture loss, moisture absorption and drug content. In vitro skin permeation studies were performed using Keshary chien cell For $24 \mathrm{~h}$ across rat skin.

Results: Chitosan was found to be a suitable polymer for matrix formation. $3.5 \% \mathrm{w} / \mathrm{w}$ was used to optimize to formulate transdermal patches. $1.5 \%$ of total solution $\mathrm{v} / \mathrm{v}$ lactic acid was used for dissolution of chitosan. $2.5 \% \mathrm{v} / \mathrm{v}$ of total solution PEG 400 was used to provide plasticity and smoothness to the patches. From the evaluation of patches formulation, F10 containing Basil oil as penetration enhancer in the concentration of $1.5 \% \mathrm{v} / \mathrm{v}$ was found to be best among all batches because of its consistent release rate For $24 \mathrm{~h}$ and extent of drug release was $85.20 \%$. It can be concluded that naturally occurring volatile oils i.e., terpenes appear acceptable permeation enhancer and shows the best permeation across skin as indicated by high percutaneous enhancement ability.

Conclusion: The developed transdermal patches are stable, non-irritating, and had increased efficacy of metoprolol and therefore had a good potential for hypertension treatment.

Keywords: Transdermal drug delivery system, Chitosan, PEG 400, Penetration Enhancers, Basil oil, Limonene, Eugenol, Urea, Sodium lauryl sulphate

(C) 2019 The Authors. Published by Innovare Academic Sciences Pvt Ltd. This is an open-access article under the CC BY license (http://creativecommons.org/licenses/by/4.0/) DOI: http://dx.doi.org/10.22159/ijap.2019v11i5.32759

\section{INTRODUCTION}

Transdermal patches are pharmaceutical preparation, which delivers drugs directly into the systemic circulation after passing through the skin barrier [1]. It is convenient for the delivery of drugs having short biological half-life.

Transdermal patches are easy to remove and apply. This approach of drug delivery is more pertinent in case of chronic disorders such as hypertension, which require long term dosing to maintain therapeutic drug concentration [2].

Transdermal delivery of therapeutic agents has been used successfully for several decades. In 1981, the first transdermal patch; Transderm Scop was developed by Alza Followed by Transderm Nitro [3]. Many other patches were introduced as motion sickness (hyoscine), cardiovascular disease (clonidine and nitroglycerin), Chronic pain (fentanyl), smoking cessation (nicotine), hormone replacement (levonorgestrel) [4].

Transdermal delivery of cardiovascular drugs offer several advantages as avoiding hepatic first-pass metabolism, maintaining constant blood level for a longer period resulting in a reduction of dosing frequency, improved bioavailability, decreased gastrointestinal irritation and improved patient compliance [5].

More than 35 TDDS products have now been approved for sale in US and approximately 16 active ingredients are approved for use in TDDS products globally. Global burden of disease study reported that there were 5.2 million deaths from cardiovascular diseases in economically developed countries and 9.1 million deaths from the same cause in developing countries. Hypertension is directly responsible for $57 \%$ of all stroke deaths in India [6].

In the present study, we aimed to deliver cardioselective betablocker, metoprolol tartrate used for the treatment of mild and moderate hypertension and also for long term management of angina pectoris. Metoprolol tartrate has a bioavailability of 40-50\% in oral dosage forms and the half-life is 3 to $7 \mathrm{~h}$. This makes frequent dosing necessary to maintain therapeutic blood levels of the drug for long term treatment. Therefore, metoprolol tartrate is ideal drug candidate for transdermal drug delivery [7]

In the present investigation, the effort has been made to enhance the bioavailability of metoprolol tartrate for the treatment of hypertension as well as angina pectoris by using various natural permeation enhancers such as basil oil, limonene, eugenol, urea and sodium lauryl sulphate. The previous studies had utilized synthetic agents but in this study natural permeation enhancers are also being explored for the bioavailability enhancement of metoprolol tartrate. Oral metoprolol tartrate has a short elimination half-life (2-3 h), and low bioavailability undergoes extensive first-pass metabolism and frequent dosing. The aim of the present investigation was to formulate, develop and evaluate metoprolol tartrate transdermal patches using various synthetic and natural penetration enhancers.

\section{MATERIALS AND METHODS}

\section{Materials}

Metoprolol tartrate was a gift sample from Ctx life science, Gujarat, India. Eugenol, limonene, sodium lauryl sulphate (sls), urea and basil oil from Central drug house. Chitosan has been received from $\mathrm{Hi}$ media. Other chemical and reagents were of analytical grades.

\section{Animals}

Wistar albino rats $150-200 \mathrm{~g}$, and immature female wistar albino rats of 21-23 d old (40-60 g) were used in this study. They were procured from animal house, Amity Institute of Pharmacy, Amity University, Noida, UP. The animals were acclimatized for ten days under laboratory conditions. They were housed in polypropylene 
cages and maintained at $27{ }^{\circ} \mathrm{C} \pm 2{ }^{\circ} \mathrm{C}$, relative humidity $65 \pm 10 \%$ under a 12-hour light/dark cycle. The animals were fed with rodent pellet diet and water ad libitum the protocol was approved by the Institutional Animal Ethics Committee (IAEC) and carried out in accordance with the Indian National Science Academy Guidelines for the use and care of animals. Animal skin was obtained from the animal house of Amity Institute of Pharmacy after CPCEA approval no. CPCSEA/AIP/2014/002.

Each experimental group had a separate set of animals and care was taken to ensure that animals used for one response were not employed elsewhere. Animals were habituated to laboratory conditions for $48 \mathrm{~h}$ prior to an experimental protocol which minimizes any nonspecific stress.

\section{Methods}

\section{Determination of melting point and solubility studies}

The melting point of the drug was determined by using Thieles tube method. The solubility of drug was determined after shaking the saturated solution of drug for $2 \mathrm{~h}$ at $25^{\circ} \mathrm{C}$ in water, chloroform, ethanol, acetone, and ether respectively.

\section{FTIR analysis}

FTIR spectra of pure drug and optimized formulation were obtained by FTIR spectrophotometer.

\section{Differential scanning calorimetry}

The DSC of the pure drug, polymer and physical mixture of drugpolymer at 1:1 was carried out.

\section{UV analysis}

The aqueous solutions of the pure drug and the patches containing metoprolol tartrate were filtered through whatmann filter paper and scanned for UV absorption between 200 and $400 \mathrm{~nm}$ [8].

\section{Development of transdermal films}

Solvent Casting method was used for the formulation of polymer matrix. The chitosan was weighed accurately as $3.5 \% \mathrm{w} / \mathrm{w}$ total solution. Chitosan was transferred to $20 \mathrm{ml}$ beaker and lactic acid $1.5 \% \mathrm{v} / \mathrm{v}$ of polymer was used to solubilize the chitosan. Beaker is kept on magnetic stirrer at a moderate speed to obtain a homogeneous mixture. PEG $4002.5 \%$ was used as plasticizer and transferred to beaker containing chitosan. Metoprolol tartrate and enhancers were added to the solution. Solution was made up to 18 $\mathrm{ml}$ with solvent and kept for $24 \mathrm{~h}$ to obtain homogeneous mixture of polymer, plasticizer and drug. After $24 \mathrm{~h}$ solution was transferred to teflon mould and was kept in oven at $40{ }^{\circ} \mathrm{C}$ overnight. After $24 \mathrm{~h}$ patches were scratched from mould. The patches thus formed were evaluated further for various parameters. The films were then packed in aluminum foil and stored in a desiccator until use at $\mathrm{RH}$ $40 \%$ and temperature $20^{\circ} \mathrm{C}[9]$.

Table 1: Composition of metoprolol transdermal drug delivery systems

\begin{tabular}{llllll}
\hline \multirow{2}{*}{ Formulation code } & Drug & Polymer & Solvent & Plasticizer & Penetration enhancer \\
\cline { 2 - 5 } & Metoprolol tartrate (mg) & Chitosan (mg) & Lactic acid (ml) & PEG 400 (ml) & \\
\hline F1 & 360 & 630 & 0.27 & 0.45 & - \\
F2 & 360 & 630 & 0.27 & 0.45 & Limonene $(0.5 \% \mathrm{v} / \mathrm{v})$ \\
F3 & 630 & 0.27 & 0.45 & Limonene $(1 \% \mathrm{v} / \mathrm{v})$ \\
F4 & 630 & 0.27 & 0.45 & Limonene $(1.5 \% \mathrm{v} / \mathrm{v})$ \\
F5 & 360 & 630 & 0.27 & 0.45 & Eugenol $(0.2 \% \mathrm{v} / \mathrm{v})$ \\
F6 & 360 & 630 & 0.27 & 0.45 & Eugenol $(0.5 \% \mathrm{v} / \mathrm{v})$ \\
F7 & 360 & 630 & 0.27 & 0.45 & Eugenol $(1 \% \mathrm{v} / \mathrm{v})$ \\
F8 & 360 & 630 & 0.27 & 0.45 & Basil oil $(0.5 \% \mathrm{v} / \mathrm{v})$ \\
F9 & 360 & 630 & 0.27 & Basil oil $(1 \% \mathrm{v} / \mathrm{v})$ \\
F10 & 360 & 630 & 0.27 & Basil oil $(1.5 \% \mathrm{v} / \mathrm{v})$ \\
F11 & 360 & 630 & 0.27 & Urea $(1 \% \mathrm{w} / \mathrm{w})$ \\
F12 & 360 & 630 & 0.27 & 0.45 & Urea $(2 \% \mathrm{w} / \mathrm{w})$ \\
F13 & 360 & 0.27 & 0.45 & Urea $(3 \% \mathrm{w} / \mathrm{w})$ \\
F14 & 360 & 0.27 & 0.45 & SLS $(0.5 \% \mathrm{w} / \mathrm{w})$ \\
F15 & 360 & 0.27 & 0.45 & SLS $(0.75 \% \mathrm{w} / \mathrm{w})$ \\
F16 & 360 & 630 & 0.45 & SLS $(1 \% \mathrm{w} / \mathrm{w})$ \\
\hline
\end{tabular}

\section{Physico-chemical evaluation of prepared transdermal patches}

\section{Weight variation}

Weight variation was determined by individually weighing randomly selected patches with the help of electronic balance. The average weight of a film and its standard deviation was calculated [10].

\section{Folding endurance}

The folding endurance would be defined as the number of folds required to break any polymeric Film. The folds on the patch have to be made at the same point, till it breaks. It was measured manually by repeatedly folding the patch at the same place till it broke. The number of folds a patch can sustain will dictate its folding endurance [11].

\section{Percentage of moisture loss}

The film was weighed accurately and placed in a desiccator containing $100 \mathrm{ml}$ of saturated solution of calcium chloride $(79.50 \%$ $\mathrm{RH}$ ). After $3 \mathrm{~d}$, the film was taken out and weighed, the percentage of moisture uptake was determined from the following formula

Percentage of moisture loss $=(\mathrm{X}-\mathrm{Y} / \mathrm{Y}) \times 100$

Where, $\mathrm{X}=$ initial weight, $\mathrm{Y}=$ final weight

\section{Percentage of moisture content}

The prepared patches are to be weighed individually and to be kept in desiccators containing fused potassium chloride $(90 \%)$ at room temperature for $24 \mathrm{~h}$. After $24 \mathrm{~h}$ the patches are to be reweighed and the percentage moisture content was determined from the following formula

Percentage of moisture content $=(\mathrm{X}-\mathrm{Y} / \mathrm{Y}) \times 100$

Where, $X=$ initial weight, $Y=$ final weight .

\section{Drug content}

The patches $\left(1.6 \mathrm{~cm}^{2}\right)$ were cut and added to the beaker containing $100 \mathrm{ml}$ of phosphate buffer of $\mathrm{pH}$ 7.4. The medium was stirred with a magnetic bead. The contents were filtered using whatmann filter and the filtrate was examined for the drug content against the solution consisting of placebo patches spectrophotometrically at the wavelengths at which calibration curve has been plotted. The experiment was repeated to validate [14].

\section{Thickness}

The thickness of transdermal patches was measured at three different places using a micrometer and the average value were calculated. 


\section{Flatness}

Longitudinal strips were cut out from the prepared medicated patch, the lengths of each strip were measured and then variation in the lengths due to the non-uniformity in flatness was measured. Flatness was calculated by measuring the construction of strips and a zero percent constriction is equal to a hundred percent flatness.

Percentage of constriction $=\left(\mathrm{I}_{1}-\mathrm{I}_{2}\right) \mathrm{I}_{2} \times 100$

Where, $\mathrm{I}_{1}=$ initial length of each strip and

$$
I_{2}=\text { final length of each strip ...... }
$$

\section{In vitro skin permeation studies}

An in vitro permeation study was carried out by using keshary-chien diffusion cell. Hair from the abdominal region was removed carefully; the skin was thoroughly cleaned with distilled water to remove any adhering tissues or blood vessels, equilibrated for an hour in phosphate buffer $\mathrm{pH} 7.4$ before starting the experiment. Diffusion cell was filled with a diffusion medium and placed on a magnetic stirrer with a small magnetic bead for uniform distribution of the diffusing. The temperature of the cell was maintained at $37 \pm 0.5^{\circ} \mathrm{C}$ using a thermostatically controlled heater. The isolated rat skin piece was mounted between the compartments of the diffusion cell, with the epidermis facing upward into the donor compartment.
A sample volume of the definite volume was removed from the receptor compartment at regular intervals and an equal volume of fresh medium is to be replaced. Samples are analyzed spectrophotometrically at wavelength $275 \mathrm{~nm}$ [16].

\section{In vitro drug release studies}

USP apparatus $\mathrm{V}$ paddle over disc method was used for assessment of the release of the drug from the prepared patches. A patch of known thickness was cut into definite shape, weighed and fixed over a glass plate with an adhesive. The paddle was then set at a distance of $2.5 \mathrm{~cm}$ from the glass plate and operated at a speed of $50 \mathrm{rpm}$. Samples were withdrawn at appropriate time intervals up to $24 \mathrm{~h}$ and analyzed by UV spectrophotometer.

Percentage of drug release was calculated using the following Formula:

Percentage drug release $=\mathrm{Da} / \mathrm{Dt} \times 100$

Where $\mathrm{Da}=$ amount of drug released

$\mathrm{Dt}=$ amount of drug in the patch

\section{Preliminary stability study of the optimized polymer matrix}

The fabricated patches were properly packed in aluminum foil and kept stability studies at the following temperature and relative humidity (RH) for one month at $25 \mathrm{C}$ and $65 \% \mathrm{RH}$ [18].

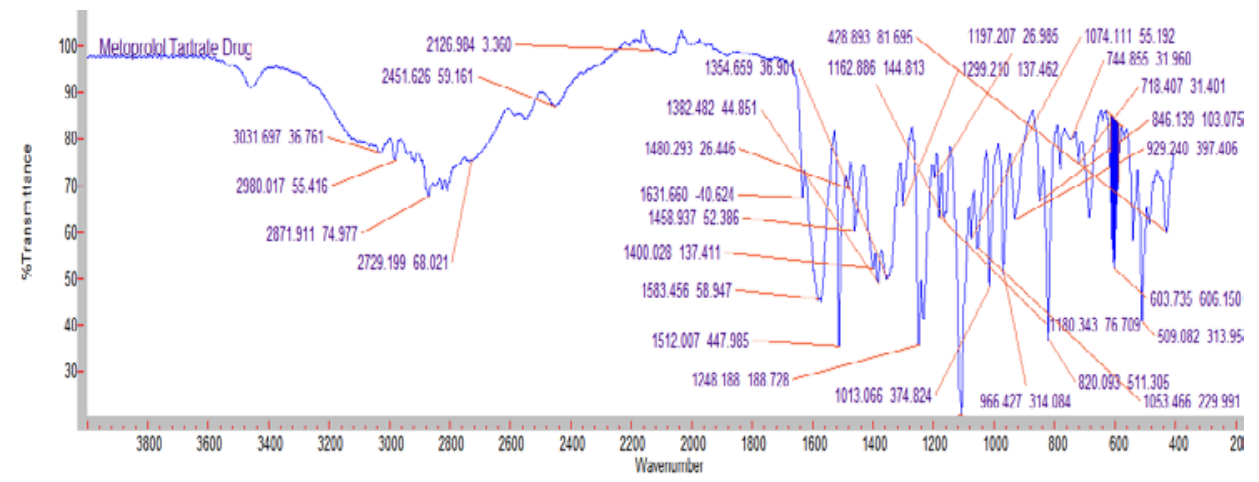

Fig. 2: FTIR of metoprolol tartrate

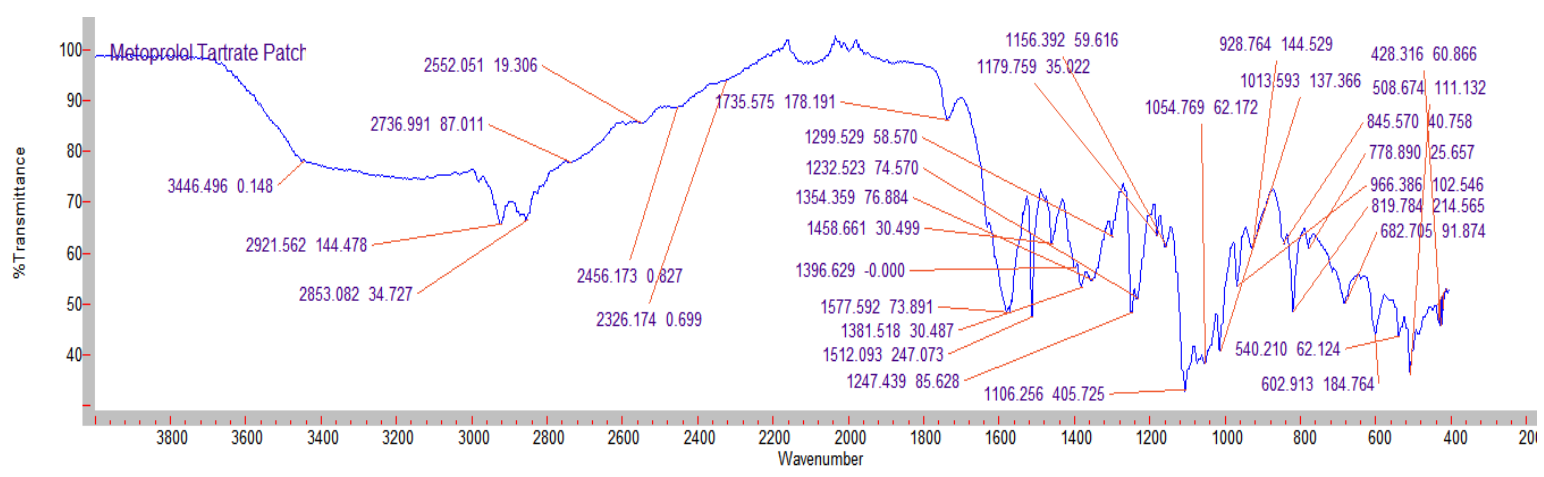

Fig. 3: FTIR of transdermal patches

\section{RESULTS AND DISCUSSION}

\section{Investigation of physicochemical compatibility of drug and polymer}

The physicochemical compatibility between the drugs and polymers used in the patches was studied by using differential scanning calorimetry (DSC). The sample was heated between $30^{\circ} \mathrm{C}$ and $300^{\circ} \mathrm{C}$ at the rate of $10{ }^{\circ} \mathrm{C} / \mathrm{min}$ in an atmosphere of nitrogen $(20 \mathrm{ml} / \mathrm{min})$. The thermograms obtained for the drug, polymers, physical mixture of drugs with polymers and formulation (patch) were compared.
The pure metoprolol tartrate peak was obtained at $125.8{ }^{\circ} \mathrm{C}$. The DSC results suggest that the drug and polymers are compatible as found in fig. 1.

\section{Drug-polymer interaction studies}

\section{FTIR spectroscopy}

The drug was characterized by FTIR spectroscopy. The spectrum was recorded using FTIR Spectrophotometer (Agilent). The scanning range was 4000 to $600 \mathrm{~cm}-1$. The spectrum of Metoprolol tartrate is shown in fig. 2. 


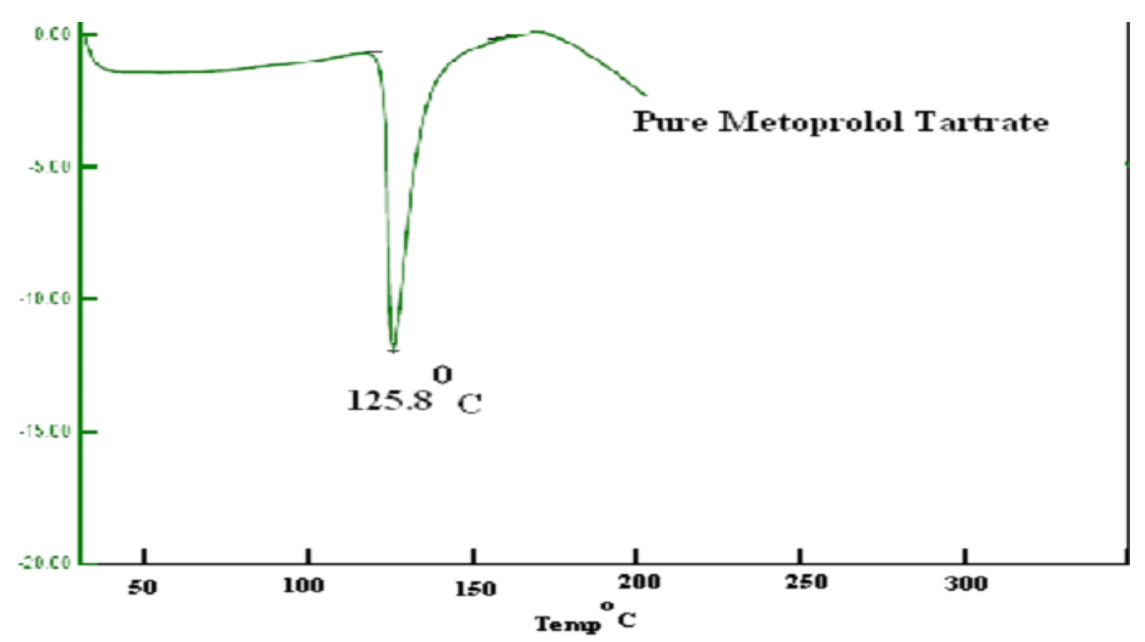

Fig. 1: DSC of metoprolol tartrate

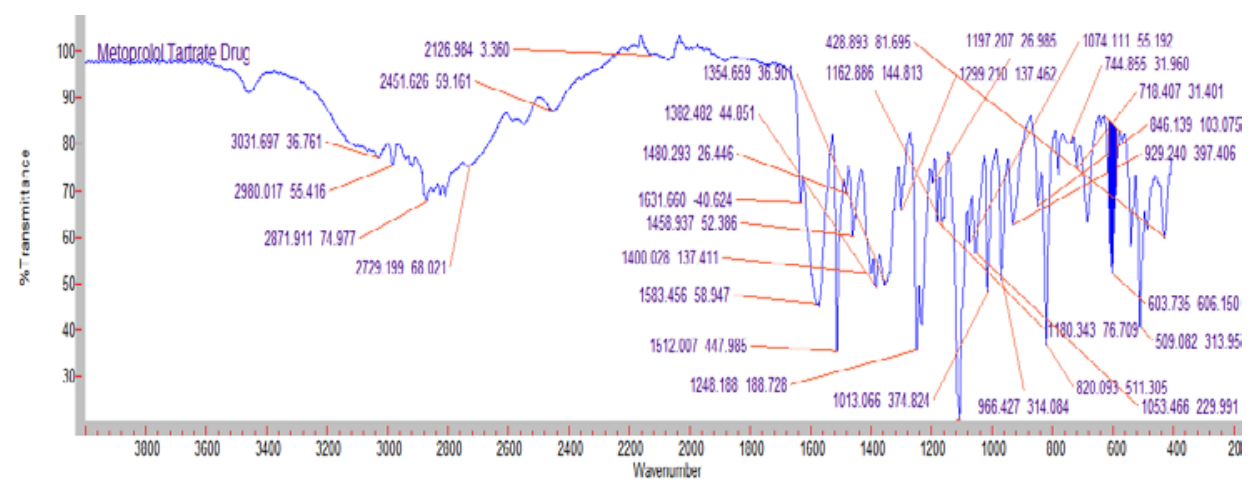

Fig. 2: FTIR of metoprolol tartrate

FTIR spectra of pure Metoprolol Tartrate, chitosan, PEG 400, lactic acid and physical mixtures of these excipients with the drug were recorded on Agilent FTIR spectrophotometer. The instrument was operated under dry air purge and the scans were collected with the resolution of $4 \mathrm{~cm}-1$ over the region $4000-400 \mathrm{~cm}-1$. The scans were evaluated for presence of principle peaks of drug, shifting and masking of drug peaks and appearance of new peaks due to polymer interaction, shown in fig. 3.

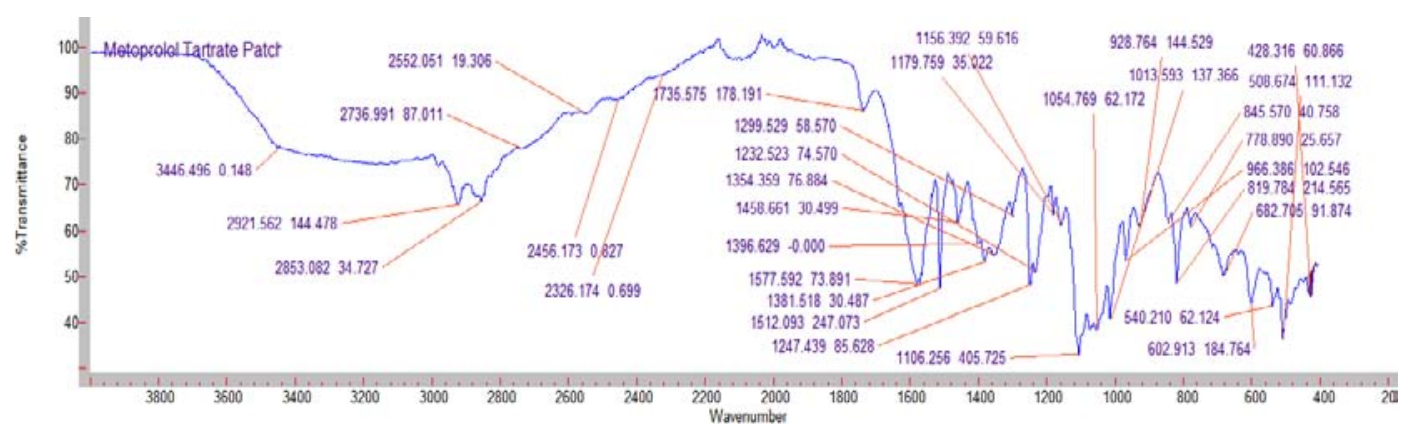

Fig. 3: FTIR of transdermal patches

\section{Physicochemical characterization of patches}

Chitosan 3.5\% w/w in combination with $1.5 \% \mathrm{v} / \mathrm{v}$ lactic acid and PEG 400 along with varying concentration of penetration enhancers (natural as well as synthetic) were used for the formulation of transdermal films in the ratios as depicted in table 1.

The results of the physicochemical characterization of the patches are shown in table 2 . The weights ranged between $426 \mathrm{mg}$ and 526 mg, which indicates that different batches' patch weights were relatively similar. Good uniformity of drug content among the batches was observed with all formulations and ranged from $78.09 \%$ to $94.25 \%$. The results indicate that the process employed to prepare patches in this study was capable of producing patches with uniform drug content and minimal patch variability. The flatness study showed that all the formulations had the same strip length before and after their cuts, indicating $100 \%$ flatness as depicted in table 2 .

Thus, no amount of constriction was observed; all patches had a smooth, flat surface; and that smooth surface could be maintained when the patch was applied to the skin. Folding endurance test 
results indicated that the patches would not break and would maintain their integrity with general skin folding when applied. The folding endurance was found to be best in the patches containing basil oil as penetration enhancers as depicted in table 2 .

The moisture content of the prepared formulations was low, which could help the formulations remain stable and reduce brittleness during long term storage. The moisture uptake of the formulations was also low, which could protect the formulations from microbial contamination and reduce bulkiness.

The moisture loss varied with different penetration enhancers. It was found that batches containing basil oil as penetration enhancers were best in terms of moisture loss since they had minimum water loss. The moisture loss was lowest in the patches without penetration enhancers as depicted in table 2 .

Table 2: Physicochemical properties of transdermal patches*

\begin{tabular}{|c|c|c|c|c|c|c|c|}
\hline $\begin{array}{l}\text { Formulation } \\
\text { code }\end{array}$ & $\begin{array}{l}\text { Folding } \\
\text { endurance } \pm S D\end{array}$ & $\begin{array}{l}\text { Weight } \\
\text { variation }(\mathrm{mg}) \pm S D\end{array}$ & $\begin{array}{l}\text { Moisture } \\
\text { loss } \\
(\%) \pm \text { SD } \\
\end{array}$ & $\begin{array}{l}\text { Moisture } \\
\text { absorption } \\
(\%) \pm \text { SD }\end{array}$ & $\begin{array}{l}\text { Drug content } \\
(\%) \pm S D\end{array}$ & $\begin{array}{l}\text { Flatness } \\
(\%)\end{array}$ & $\begin{array}{l}\text { Thickness } \\
(\mathrm{mm}) \pm \mathrm{SD}\end{array}$ \\
\hline F1 & $198 \pm 2.21$ & $426 \pm 0.005$ & $2.23 \pm 0.02$ & $4.0 \pm 0.005$ & $78.09 \pm 0.0432$ & 100 & $0.53 \pm 0.007$ \\
\hline $\mathrm{F} 2$ & $180 \pm 2.23$ & $523 \pm 0.004$ & $4.92 \pm 0.07$ & $3.59 \pm 0.061$ & $80.66 \pm 0.023$ & 100 & $0.52 \pm 0.017$ \\
\hline F3 & $189 \pm 2.20$ & $521 \pm 0.002$ & $3.62 \pm 0.03$ & $5.1 \pm 0.025$ & $88.12 \pm 0.029$ & 100 & $0.53 \pm 0.010$ \\
\hline F4 & $190 \pm 2.27$ & $526 \pm 0.002$ & $4.71 \pm 0.05$ & $6.21 \pm 0.021$ & $89.67 \pm 0.039$ & 100 & $0.55 \pm 0.016$ \\
\hline F5 & $188 \pm 2.36$ & $524 \pm 0.003$ & $2.94 \pm 0.06$ & $4.18 \pm 2.21$ & $80.18 \pm 0.051$ & 100 & $0.53 \pm 0.015$ \\
\hline F6 & $195 \pm 2.78$ & $520 \pm 0.001$ & $3.28 \pm 0.02$ & $6.12 \pm 1.98$ & $87.20 \pm 0.042$ & 100 & $0.51 \pm 0.012$ \\
\hline F7 & $191 \pm 3.21$ & $522 \pm 0.001$ & $5.23 \pm 0.04$ & $8.49 \pm 1.99$ & $90.32 \pm 0.051$ & 100 & $0.55 \pm 0.015$ \\
\hline F8 & $200 \pm 1.23$ & $510 \pm 0.002$ & $2.12 \pm 0.03$ & $4.08 \pm 0.22$ & $82.03 \pm 0.005$ & 100 & $0.52 \pm 0.018$ \\
\hline F9 & $193 \pm 1.45$ & $498 \pm 0.003$ & $3.72 \pm 0.01$ & $3.07 \pm 0.12$ & $91.53 \pm 0.023$ & 100 & $0.55 \pm 0.016$ \\
\hline F10 & $203 \pm 1.89$ & $493 \pm 0.002$ & $1.28 \pm 0.03$ & $3.02 \pm 0.22$ & $94.25 \pm 0.09$ & 100 & $0.54 \pm 0.019$ \\
\hline F11 & $172 \pm 2.22$ & $499 \pm 0.004$ & $2.52 \pm 0.05$ & $4.2 \pm 0.006$ & $89.20 \pm 0.028$ & 100 & $0.53 \pm 0.013$ \\
\hline F12 & $185 \pm 2.34$ & $500 \pm 0.006$ & $3.89 \pm 0.06$ & $2.5 \pm 0.002$ & $90.15 \pm 0.02$ & 100 & $0.55 \pm 0.015$ \\
\hline F13 & $187 \pm 3.21$ & $497 \pm 0.002$ & $4.50 \pm 0.02$ & $3.23 \pm 0.005$ & $89.25 \pm 0.024$ & 100 & $0.56 \pm 0.012$ \\
\hline F14 & $197 \pm 2.10$ & $495 \pm 0.001$ & $3.01 \pm 0.05$ & $4.82 \pm 0.281$ & $88.10 \pm 0.0432$ & 100 & $0.52 \pm 0.016$ \\
\hline F15 & $196 \pm 2.45$ & $494 \pm 0.003$ & $5.64 \pm 0.02$ & $2.28 \pm 0.22$ & $90.12 \pm 0.044$ & 100 & $0.54 \pm 0.019$ \\
\hline F16 & $192 \pm 2.98$ & $496 \pm 0.003$ & $4.93 \pm 0.03$ & $3.69 \pm 0.226$ & $86.99 \pm 0.042$ & 100 & $0.55 \pm 0.011$ \\
\hline
\end{tabular}

*All values are expressed as mean \pm SD $(n=10)$.

Table 3: In vitro cumulative drug release of metoprolol transdermal drug delivery systems

\begin{tabular}{lll}
\hline S. No. & Formulation code & Cumulative percentage drug release \\
\hline 1 & F1 & $58.03 \pm 1.90$ \\
2 & F2 & $69.86 \pm 0.90$ \\
3 & F3 & $72.5 \pm 1.99$ \\
4 & F4 & $79.26 \pm 1.09$ \\
5 & F5 & $69.12 \pm 1.23$ \\
6 & F6 & $75 \pm 1.98$ \\
7 & F7 & $80.12 \pm 1.54$ \\
8 & F8 & $80.12 \pm 1.54$ \\
9 & F9 & $75.5 \pm 1.90$ \\
10 & F10 & $85.201 \pm 0.30$ \\
11 & F11 & $60.96 \pm 1.19$ \\
12 & F13 & $72.5 \pm 1.98$ \\
13 & F14 & $75.22 \pm 1.67$ \\
14 & F15 & $58.07 \pm 1.65$ \\
15 & F16 & $65.521 \pm 1.23$ \\
16 & & $60.25 \pm 0.45$ \\
\hline
\end{tabular}

*All values are expressed as mean \pm SD $(n=10)$

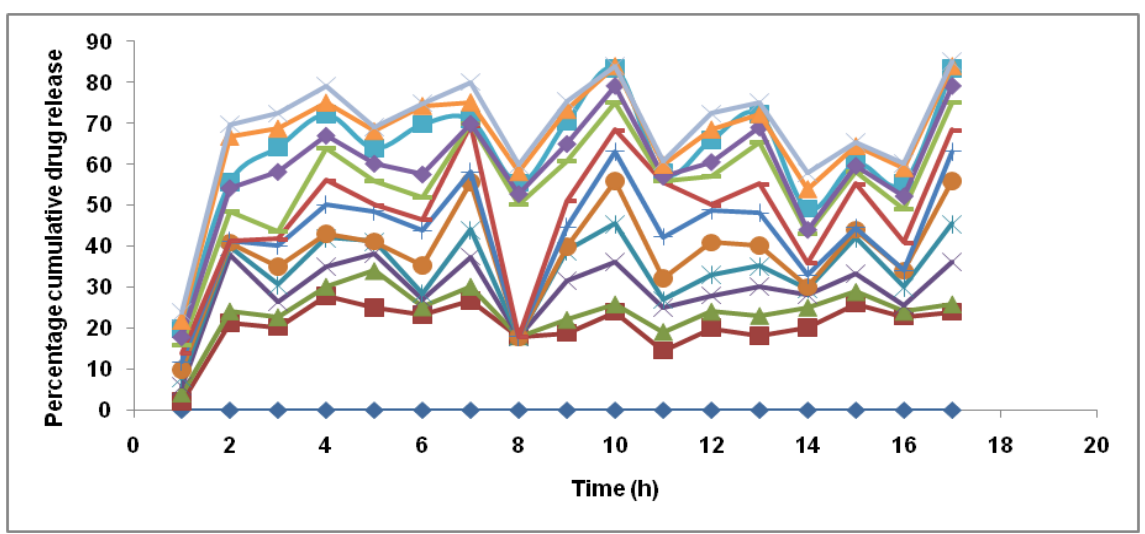

Fig. 4: In vitro skin permeation profile of metoprolol from transdermal patches, data are mean $\pm S E(n=6)$ 


\section{In vitro skin permeation studies}

The in vitro skin permeation studies were carried out using keshary chien cell for a period of $24 \mathrm{~h}$. The patches were $15 \mathrm{~cm}^{2}$ in area and were prepared by solvent casting method by using PEG 400 as a plasticizer. In order to know whether the patches would release drug in desired fashion in vitro permeation studies in Keshary chien cell was carried out. Along with that, diffusion studies were also evaluated in phosphate buffer $\mathrm{pH} 7.4$ [23-25] The in vitro permeation of various formulations were the in vitro release of formulations from F1 to F16 were found in the range of $58.03 \%$ to $80.20 \%$, as depicted in table 3. From the evaluation of patches formulation, F10 containing basil oil as penetration enhancer in the concentration of $1.5 \% \mathrm{v} / \mathrm{v}$ was found to be best among all batches because of its consistent release rate for $24 \mathrm{~h}$ and extent of drug release was $85.20 \%$ as depicted in fig. 4 and table 3. The formulation F10 have achieved highest drug release as compared to other polymers.

\section{CONCLUSION}

The patches are containing basil oil as penetration enhancer were best in terms of physicochemical properties as well as drug release. The formulation F10 was found to be best among all batches because of its consistent release rate for $24 \mathrm{~h}$, and extent of drug release was $85.20 \%$. It can be concluded that naturally occurring volatile oils i.e., terpenes appear acceptable permeation enhancer and shows the best permeation across skin as indicated by high percutaneous enhancement ability.

The developed transdermal patches are stable, non-irritating and had increased efficacy of metoprolol and therefore had a good potential for hypertension treatment. However, pharmacodynamics and pharmacokinetic evaluation of these systems in human volunteers is necessary to confirm these findings.

\section{ACKNOWLEDGMENT}

The authors wish to thank Amity Institute of Pharmacy, Amity University, Noida for providing all the facilities for carrying out the research.

\section{AUTHORS CONTRIBUTIONS}

All the authors have contributed equally.

\section{CONFLICT OF INTERESTS}

The authors report no conflicts of interest

\section{REFERENCES}

1. Tripathi KD. Essential of medical pharmacology. $6^{\text {th }}$ ed; 2010;6:539.

2. Sharma HL, Sharma KK. Principle of pharmacology. $1^{\text {st }}$ Edition; 2011. p. 19.

3. Wexler R, Aukerman G. Non pharmacological strategies for managing hypertension. Am Fam Physician 2006;11:1953-6.

4. MahFoud Felix, Himmel Frank, Ukena Christan, Schunkert Heribert, Bohm Michael, Weil Joachim. Treatment strategies for resistant arterial hypertension. Dtsch Arztebl 2011;43:725-31.

5. Zamanian TR, Haddad Francois, Doyle LR, Weinacker BA. Management strategies for patient with pulmonary hypertension in the intensive care unit. Crit Care Med 2007;35:2037-50.
6. Sowmya C, Suryaprakash Reddy C, Amrutha V, Anil Kumar D, Lohitha M. Transdermal therapeutic systems. Int J Pharm Industrial Res 2012;2:197-211.

7. Rastogi V, Pragya, Upadhyay P. A brie $F$ view on antihypertensive drugs delivery through transdermal patches. Int J Pharm Sci Res 2012;3:1955-70.

8. Patel D, Patel N, Parmar M. Transdermal drug delivery systems: review. Int J Pharm Toxic Res 2011;1:61-80.

9. Patel D, Chaudhary SA, Parmar, Bhura N. Transdermal drug delivery system: an review. Pharma Innovation 2012;4:78-87.

10. Prabhakar D, Sreekanth J, Jayaveera KN. Transdermal drug delivery patches: a review. J Drug Delivery Ther 2013;3:213-21.

11. Yadav V, Sipai A, Mamatha Y, Prasantha V. Transdermal drug delivery: a technical write up. J Pharm Sci Innovation 2012;1:512.

12. Mudavath Hanumanaik, Patel D, Kumar G, Patel SK, Singh I. Design, evaluation and recent trends in transdermal drug delivery system. Int J Pharm Sci Res 2012;3:2393-406.

13. Dhangwal M. Transdermal drug delivery system. Pharma tutor; 2015.

14. John L, Kumar A. Comparison of amlodipine transdermal patch using HPMC and chitosan. Asian J Pharm Clin Res 2014;7:8690.

15. Satheeshababu BK, Kumar SKL. Synthesis of conjugated chitosan and its effect on drug permeation from transdermal patches. Indian J Pharm Sci 2013;75:162-70.

16. Can AS, Erdal MS, Gungor S. Optimization and characterization of chitosan films for transdermal delivery of ondansetron. Molecules 2013;18:5455-71.

17. Madhulatha A. Formulation and evaluation of transdermal patches. Int J Res Pharm Med Sci 2013;4:351-62.

18. Balamurugan M, Agrawal SS. Formulation and evaluation of chitosan-based bioadhesive transdermal drug delivery system of lisinopril for prolonged drug delivery. Pharm Sin 2013;4:1-7.

19. Chauhan SB, Naved T. Formulation and development of transdermal drug delivery system of ethinylestradiol and medroxyprogesterone acetate for antifertility treatment. Int J ChemTech Res 2017;10:1164-71.

20. Chauhan SB, Naved T. Formulation and development of transdermal drug delivery system of antifertility drugs using a combination of polymers. Int J Pharma Bio Sci 2017;8:30-5.

21. Chauhan S, Naved T, Parvez N. Formulation and development of transdermal drug delivery system of ethinylestradiol and testosterone: in vitro evaluation. Int J Appl Pharm 2019;11:55-60.

22. Chauhan S, Naved T, Parvez N. Effect of hydrophilic and hydrophobic polymer matrix on the transdermal drug delivery of ethinylestradiol and medroxyprogesterone acetate. Int J Appl Pharm 2019;11:210-5.

23. Chauhan SB, Naved T, Parvez N. Formulation development and evaluation of proniosomal gel of ethinylestradiol and levonorgestrel for antifertility treatment. Asian J Pharm Clin Res 2019;12:364-8.

24. Denge MS, Walde SR, Ittadwar AM. Development and characterization of transdermal patches of ondansetron hydrochloride. Int J Pharm Pharm Sci 2012;4:293-8.

25. Jadhav JK, Sreenivas SA. Formulation and in vitro evaluation of indomethacin transdermal patches using polymers HPMC E5 and ethyl cellulose. Int J Pharm Pharm Sci 2012;4:550-6. 